\title{
Quantum Randomness is Chimeric
}

\author{
Karl Svozil (D)
}

check for

updates

Citation: Svozil, K. Quantum Randomness is Chimeric. Entropy 2021, 23, 519. https://doi.org/ 10.3390/e23050519

Academic Editor: Remigiusz Augusiak

Received: 2 March 2021

Accepted: 20 April 2021

Published: 24 April 2021

Publisher's Note: MDPI stays neutral with regard to jurisdictional claims in published maps and institutional affiliations.

Copyright: (C) 2021 by the author. Licensee MDPI, Basel, Switzerland. This article is an open access article distributed under the terms and conditions of the Creative Commons Attribution (CC BY) license (https:// creativecommons.org/licenses/by/ $4.0 /)$.
Institute for Theoretical Physics, TU Wien, Wiedner Hauptstrasse 8-10/136, 1040 Vienna, Austria; svozil@tuwien.ac.at

\begin{abstract}
If quantum mechanics is taken for granted, the randomness derived from it may be vacuous or even delusional, yet sufficient for many practical purposes. "Random" quantum events are intimately related to the emergence of both space-time as well as the identification of physical properties through which so-called objects are aggregated. We also present a brief review of the metaphysics of indeterminism.
\end{abstract}

Keywords: quantum randomness; Gleason theorem; Kochen-Specker theorem; Born rule; object construction; emergent space-time; quantum entanglement

PACS: 03.65.Ca; 02.50.-r; 02.10.-v; 03.65.Aa; 03.67.Ac; 03.65.Ud

\section{Quantum Oracles for Randomness}

Almost 40 years since the glamorous inception [1-5] of quantum computing, and despite numerous grandiose claims and prospects of quantum computational advantages [6-8], only the random generation of bit sequences by beam splitters [9-17] has reached a certain commercial [18] maturity. Yet, these quantum random number generators present oracles $[9,19]$ for "randomness", which (i) inductively are imagined and extrapolated to be a finitistic version of an essentially transfinite concept [20]. "Certifications" by NIST and DIEHARD and other sophisticated test suites are of little consolation; and other natural resources for randomness exhibit similar performances [14,17]; and (ii) deductively are certifiable merely relative to the principles, assumptions, and axioms-such as, for instance, complementarity or "contextuality" [12,16,21,22]-they are based upon. It is therefore of utmost importance to carefully delineate and be aware of these latter presumptions if we want to certify and trust such devices.

In what follows, we shall discuss randomness "extracted" from measurements of coherent superpositions of classically mutually exclusive states, then proceed to multipartite and mixed states. No quantum field theoretic many-particle effects such as stimulated or spontaneous emission or decay will be mentioned. In the later parts of the paper, we shall attempt a brief history of physical events that have been deemed "random" and, in particular, their relationship to the metaphysical ideas implied.

I encourage the reader to consider some of the content speculative and challengingnot as disrespectful to proposals and operationalizations of quantum randomness, including some earlier ones I myself contributed to [9,12,15,23] — but as reflections on some aspects that might be noteworthy and even troubling. A recent "canonical" presentation of quantum randomness in a broad perspective can be found in Reference [24]. One might also add that certain interpretations of Everett's relative state formulation [25] suggest similar conclusions, albeit for very different reasons: that randomness is an intrinsic illusion [26].

\subsection{Quantum Randomness through the Measurement Problem}

Quantum mechanics allows the coherent superposition (or, by another denomination, linear combination) of states which correspond to mutually exclusive outcomes. The question arises: what kind of physical meaning can be given to these "self-contradictory" 
states? Furthermore, is it not amazing that, for such states, there exist two types of very closely related measurements that give vastly different results: one random and one not?

Let me explain this question in some more detail for an ideal configuration, thereby neglecting observational (or measurement) errors; in particular, no stochastic or random errors are taken into account. Suppose one prepares a pure quantum state, say, by preselecting certain outcomes of beam splitter experiments. (By similar arguments as the ones exposed here the randomness of mixed states are epistemic rather than ontic, and therefore, for all practical purposes, chimeric as well.) If one "measures" these pre-selected states again and again by serial composition of either identical beam splitters, or "contextual intertwined" beam splitters, one of whose output ports "shares" (and corresponds to) the pre-selected state [27-30], then a detector registering (or post-selecting) the "resulting" states ("after such serial processing") will always click with certainty. That is to say, such an experiment reveals a strictly deterministic, absolutely predictable behavior of this pre-selected quantum state.

Even the slightest physical "tilt" or "rotation" of one of the serially composed beam splitters changes the situation entirely and dramatically: according to the standard quantum narrative, the experiment suddenly and discontinuously "performs indeterministically", such that individual events—or at least post-processed sequences of such individual events-turn out to be irreducibly random [31] (relative to maybe "mild" side assumptions, such as independence, any bias can be eliminated by (Borel) normalization [32-34]). Such a physical manipulation of the beam splitter-literally "tilting" or "rotating" it—-translates into a unitary transformation; that is, a generalized "rotation", of the state (or context) or (by the dyadic products) the respective observable proposition(s) in Hilbert space. A "slight detuning" associated with a "small" change of the post-selected context with respect to the pre-selected context will not "throw the outcomes into crazy randomness". Indeed, the quantum probability is a smooth function of detuning, so a "slight detuning" will only introduce a "small" amount of indeterminism in the raw data extracted. Nevertheles, relative to certain mild side assumptions such as independence of events, any such "tiny signal" of indeterminism in the raw data can be "amplified into crazy randomness" by (Borel) normalization, such as von Neumann's [32] partitioning of the raw data sequence into subsequences of length two, and then mapping $00 \mapsto \varnothing, 11 \mapsto \varnothing, 01 \mapsto 0$, and $10 \mapsto 1$. This sudden, discontinuous change from determinism into complete indeterminism by some "smooth, continuous" manipulation boggles a mind prepared to "evangelically" $[35,36]$ accept the quantum canon.

For the sake of a concrete example, take $|\psi\rangle=\psi_{0}|0\rangle+\psi_{1}|1\rangle=\left(\psi_{0}, \psi_{1}\right)^{\top}$ with $\left|\psi_{0}\right|^{2}+$ $\left|\psi_{1}\right|^{2}=1$ and ( $\mathrm{T}$ stands for transposition), $|0\rangle=(1,0)^{\top}$ and $|1\rangle=(0,1)^{\top}$. Suppose we prepare or pre-select the quantized system to be in the state $|\psi\rangle=\frac{1}{\sqrt{2}}(|0\rangle+|1\rangle)=$ $\frac{1}{\sqrt{2}}(1,1)^{\top}$, and we prefer to measure an observable $|\psi\rangle\langle\psi|$ (that appears "rotated" or transformed relative to the observables $|0\rangle\langle 0|$ and $|1\rangle\langle 1|)$. In such a case, the system presents itself as being perfectly determined and value definite; with the respective outcome always occurring. No randomness or value definiteness can be ascribed to such a configuration. (Value definiteness shall be understood as "possessing" a well-defined property, encodable by some mathematical entity. In terms of (ideal) measurements, value definite properties yield the respective outcomes with certainty.) With respect to $|\psi\rangle\langle\psi|$ and its perpendicular orthogonal projection operator $\mathbf{1}_{2}-|\psi\rangle\langle\psi|$ there is no uncertainty, and no possibility to obtain randomness.

Randomness comes about if "detuned experiments" are performed, such as, for instance, the ones "measuring observables" corresponding to the orthogonal projection operators $|0\rangle\langle 0|$ and $|1\rangle\left\langle 1\left|=\mathbf{1}_{2}-\right| 0\right\rangle\langle 0|$. This concrete example features maximally or mutually unbiased [37] bases; but any "tiny" rotation $0 \neq \varphi \ll 1$, with $\psi_{0}=\cos \varphi$ and $\psi_{1}=\sin \varphi$ suffices to yield irreducible randomness through (Borel) normalization, as mentioned earlier.

An immediate question arises: why should such "tilted" or "detuned" experiments yield any results at all, and if so, in what way do outcomes of such "wrong experiments" 
come about; and to what extent do they reflect any intrinsic property of the pre-selected state $|\psi\rangle$ ? It is rather mind-boggling that one should get any answer at all from such queries or "detuned" measurements. However, this may be as confounding as it may be deceptive: because one might get the impression that there is a physical property "out there", "sticking" and being associated with the state. I believe that mistakenly interpreting an experimental outcome-such as a detector click - as some inherent property, constitutes a major epistemological issue that underlies many ill-posed claims and confusions about such quantum states. Indeed, these misconceptions may epitomize erroneous claims upon which quantum number generators by "quantum coin tosses" are based.

The quantum measurement problem is relevant for any judgment or certification or opinion on quantum randomness: "extracting" or "reducing" such states as $|\psi\rangle$ by "measuring" them in the "wrong and detuned" basis $|0\rangle$ and $|1\rangle$, different from $|\psi\rangle$ and its orthogonal vector, lies at the heart of the quantum measurement problem. The respective "process", just as taking (partial) traces, is non-unitary because it is postulated "manyto-one" and irreversible. Therefore, such "processes" are inconsistent with the unitary quantum evolution, which is "one-to-one" and reversible. (see Section 1.8 of Ref. [5] for a nice presentation.)

This inconsistency is an old issue that has already been raised by von Neumann [38,39], Schrödinger [40-42], London and Bauer [43,44], Everett [25,45,46], and Wigner [47]. It can be developed as a "nesting" or "inverse Russian doll" type argument by ever-increasing the domain of unitarity; including the measurement apparatus and the measured state, and hence the interface or cut "between" them. This has been proposed and operationalized in quantum optical experiments reconstructing the coherent superposition of states after "measurements" [48-56], as well as in discussions about the insurmountable practical difficulties in doing so $[57,58]$.

Strictly speaking, by assuming irreversible many-to-one "processes", one has to go beyond quantum mechanics in an ad hoc fashion. Presently, there is no evidence suggesting that this is necessary or even consistent with empirical data. Should quantum mechanics be extended against all experimental evidence, just because it is theoretically convenient and saves primitive notions of "measurement"?

\subsection{Objectification by Emergent Context Translation}

In what follows, it will be argued that any kind of measurement-in particular, also associated with "detuned experiments" - constitutes an object or reality construction, whereby the conventionality of measurement plays an essential role. In this process, the very notion of objects or physical properties becomes conventionalized. Objects or the properties constituting them may be real or chimeric; in the latter, chimeric case those experiments relate to properties the system is fantasized about, but not encoded in [59]. In a metaphorical sense, this is like map-making or the creation of an encyclopedia, in which entries are constituted as facts or fiction, or in any other way that is supposed to be consensical or intentional.

The term "chimeric" will be associated with coherent superpositions or linear combinations of different (mutually orthogonal) states, relative to those states or their associated observable propositions involved. For instance, $|\psi\rangle=\psi_{0}|0\rangle+\psi_{1}|1\rangle$ with nonzero $\psi_{1}$ and $\psi_{2}$ is chimeric relative to the propositions $|0\rangle\langle 0|$ and $|1\rangle\langle 1|$; but is value definite, or "real", and not chimeric relative to $|\psi\rangle\langle\psi|$. States are not chimeric relative to the propositions associated with those exact states, that is, $|\psi\rangle$ is "real" and not chimeric relative to $|\psi\rangle\langle\psi|$.

The emergent process of "creating chimeras" will be called "objectification" or object emergence or (re)construction. Objectification is related to an ancient conundrum [60]: the Ship of Theseus, or more generally, what is in Philosophy called "the problem of identity" [61,62]. In the physical measurement process, it is the question of how, through "mediation" of its environment and the measurement apparatus, a physical state or system which initially is unprepared to answer a particular query—or, stated differently, is value indefinite and chimeric- "translates" the respective "detuned" query such that it is can 
respond to the request. Through this "context translation", it may have acquired signals and information exterior to itself, which may render the answer stochastic relative to itself (because of an influx from the open environment) and to the experimental means available $[63,64]$ (containing or severing that open environment).

One might object that this stance reiterates a well-known fact: that quantum measurement introduces stochasticity. The point of departure from this common view is the emphasis on the "nesting" aspect of the situation, as outlined already by Everett [25] and Wigner [47]; but unlike them, more in the spirit of statistical physics: In a Maxwellian view [65], the stochastic behavior (and entropy increase) originates from sampling-from not looking at the micro-physical level, but at some "aggregates"—rather than taking this for granted.

This has consequences for the stochasticity of chimeras: they are not only based on some property intrinsic to the object, but on the combined context by which the object, as well as the apparatus, is defined [66]. Stochasticity enters by the many degrees of freedom of such a combined system. This kind of emergence of an "experimental outcome" associated with a counter reading of a (macroscopic) measurement apparatus has already been modeled (i) by a coupling of the object with the apparatus and its environment [67], and (ii) by "attenuating" a quantum signal from a state to cloning a "noisy multitude" of this state [68,69] (it is always possible to clone two fixed orthogonal states) "as much as possible" (that is, nothing at all) within the framework of the no-cloning theorem (cf. Section 2.1 of Ref. [5]).

For the sake of understanding on which basis claims of absolute randomness are raised beyond evangelical confessions [31,36], let me reconstruct current "best-practice arguments" for quantum indeterminacy [70] and value indefiniteness [22,71] and their counterfactual [72,73] character. There "exist" collections of (counterfactual [72]) observables comprising intertwining contexts (formalized by orthonormal bases or maximal operators in dimension three or higher) with two terminal point states-one serving as pre-selection or preparation, the other one for postselection or "measurement" - with the following inconsistent properties: Upon pre-selection or preparation of a particular state $|\Psi\rangle$, (i) one such collection of observables enforces the nonoccurrence of some post-selected state $|\Phi\rangle$, associated with a certain negative experimental result; (ii) another one such collection of observables enforces the occurrence of some post-selected state $\left|\Phi^{\prime}\right\rangle$, associated with a certain positive experimental result [74,75]; (iii) both post- and pre-selected states are the same, say, $|\Psi\rangle=(1,0,0)^{\top}$ and $|\Phi\rangle=\left|\Phi^{\prime}\right\rangle=(1 / 2)(\sqrt{2}, 1,1)^{\top}[22,71,76]$. Figure 1 sketches such a configuration. The classical inconsistency arises from the fact that, depending on the arrangement of the quantum observables, the same observable must either be false (snake-like decorated curve) and true (zigzag-like decorated curve) at the same time-a complete contradiction amounting to the absurd prediction that a detector associated with such a binary observable simultaneously registers a click and does not do so. Relative to the assumptions made $|\Phi\rangle$ given $|\Psi\rangle$ cannot have a classical value definite truth assignment: any such truth assignment would need to be undefined at least for $|\Phi\rangle$. This yields the truth assignment as a partial function, a notion well known in theoretical computer science [77] The argument can be extended to any state not collinear with or orthogonal to the pre-selected state $|\Psi\rangle$ [22]. 


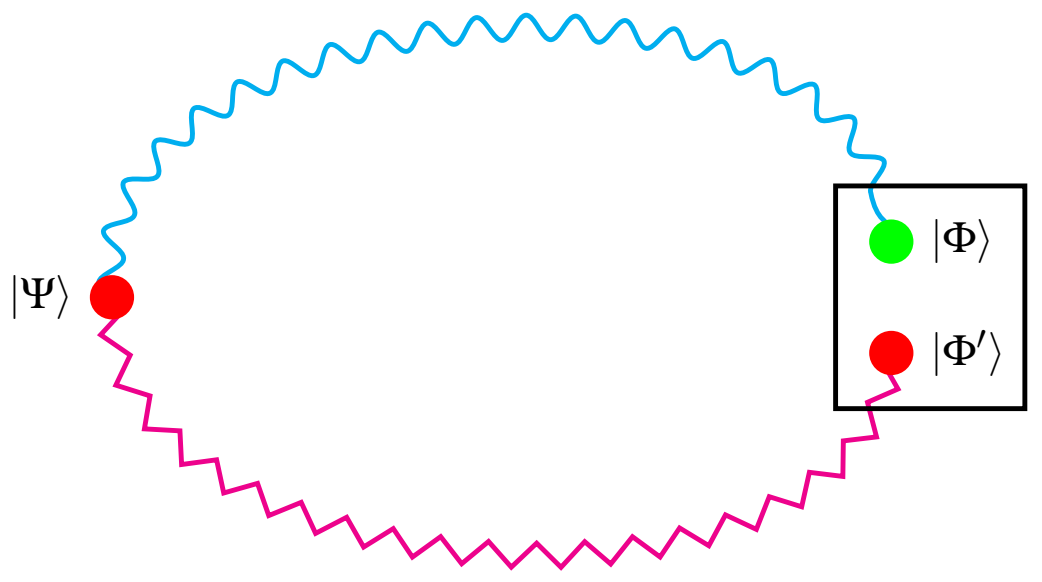

Figure 1. Serial composition of two gadget hypergraphs with terminal points $|\Psi\rangle$ and approaching $|\Phi\rangle \leftrightarrow\left|\Phi^{\prime}\right\rangle$. The snake-like decorated curve indicates a classical true-implies-false relation. The zigzag-like decorated curve indicates a classical true-implies-true relation.

Another implicit assumption that is seldom mentioned because it is assumed evident is the omni-existence of the collection of complementary observables (because the argument involves different contexts). Indeed, the coexistence of counterfactual, complementary observables is (mostly implicitly) assumed without further discussion. One common response to critical doubts about their existence is that "they can be measured". That is, a particular state $|\psi\rangle$ can be prepared or pre-selected and subsequently, the proposition corresponding to another "mismatching" state $|\varphi\rangle$ (which should neither be orthogonal to, nor collinear with, $|\psi\rangle$ ) can be measured or post-selected. This, of course, is omni-realism, pure and simple.

Coming back to the argument sketched in Figure 1, it is evident that, due to preselection or preparation, the state $|\Psi\rangle$ and its associated observable proposition $|\Psi\rangle\langle\Psi|$ is value definite relative to measurements $|\Psi\rangle\langle\Psi|$. However, should this be assumed for all the other observables entering the argument? In particular, should value definiteness be expected from some state $|\Phi\rangle$ given $|\Psi\rangle$ ? Because $|\Phi\rangle$, and all other observables, entering as counterfactual "intermediaries" in the argument, need to be in a coherent superposition of states different from the pre-selected state $|\Psi\rangle$ and other states, which makes them chimeric relative to $|\Psi\rangle$.

\subsection{Information Theoretic Approach to Quantum Randomness}

A related information-theoretic argument for "irreducible" [31] quantum randomness contends that a quantum system can "carry" only a finite amount of information $[59,78,79]$ namely (maximally) about the occurrence of a single proposition within a single context. Therefore, the [59] “. . reason for the irreducible randomness in quantum measurement ... is the simple fact that an elementary system cannot carry enough information to provide definite answers to all questions that could be asked experimentally". Stated differently [80], "there are less available answers than possible questions". Any query attempting to forcefully retreive "more" information from such a quantized system is confronted with this "underdetermination", resulting in ontological indeterminism.

Alternatively, one might argue that this "insistance on the enforced retrieval of information the quantum system is unprepared to hold" results in a context translation. Typical examples are "detuned experiments" mentioned earlier, associated with an influx of information from the environment and, in particular, the measurement apparatus. This effectively results in epistemic quantum indeterminism.

One could still maintain that, through nesting $[25,47]$ and the effects of the translational environment the number of degrees of freedom during the measurement cannot 
be bounded from above and approaches infinity, resulting in nonseparable hyper-Hilbert spaces [81], a situation which might yield a sort of irreducible randomness based on the diverging complexity of the environment [82]. Note that even classically the hypothetical invocation of infinity "in the limit produces" provable random sequences, such as Chaitin's halting probability Omega [83].

\subsection{Entanglement and Emergence of Space-Time}

Einstein's primary intent [84-86] in writing a paper with Podolsky and Rosen [87] (EPR) was to present a separation principle or separation hypothesis: given any two (spacelike) separated subsystems $A$ and $B$ of a joint system $(A B)$, then $B$ (my translation, see also [86]) "and everything related to its content is independent of what happens with regard to" $A$. Thereby, Einstein's presumption has been that, after any interaction between $A$ and $B$ in the past (quoted from the same letter, my translation, see also [86]) "the real state of $(A B)$ consists of the real state of $A$ and the real state of $B$, which two states have nothing to do with one another".

This latter assumption, at least for Einstein, is one pillar of the EPR argument. However, suppose that we are not inclined to follow Einstein's critique of quantum mechanics, but propose that, rather than quantum theory, space-time physics, and relativity theory would need to adapt in case there is a collision with quantum mechanics. Then the separation principle should be considered incorrect and not be applied for entangled quantum states introduced by Schrödinger $[40,41,88,89]$ around the time of the EPR paper. In particular, there exist entangled states of two subsystems $A$ and $B$ which are indecomposable; that is, they cannot be written as the product of the states of the two "separated" systems $A$ and $B$; more formally, $|\Psi(A B)\rangle \neq|\psi(A)\rangle \otimes|\phi(B)\rangle$, where $\otimes$ stands for the tensor product.

This inseparability, as discussed by Schrödinger in the measurement context (between object and measurement apparatus) has been re-interpreted in terms of relational properties [59] for multi-partite configurations. It comprises two parts-a restrictive and an extensive property for classical physical systems: (i) quantum mechanics limits the amount of information encodable in a quantized system from above; and (ii) it allows the storage, resampling [90], or scrambling of such limited information "across quanta". Both properties can be viewed as direct consequences of the unitary transformations postulated as formalizations of quantum state evolution, because entangled systems are merely "a unitary transformation apart" from separable states ([91], Section 12.8.2).

Let us pursue a very radical, iconoclastic deviation from the Kantian idea that spacetime is an a priori theatric frame, a sort of scaffolding, in which physics takes place. Rather, suppose that

(i) in reversing Einstein's verdict mentioned earlier, for (maximally) entangled states of a composite system $(A B)$, its constituents share a common identity-that is, they "are tied together" and can be considered "being aspects of a single entity" and, in particular, "not spatio-temporally separated at all"; so much so that any individuality or separateness vanishes.

(ii) Space-time needs to be derived from quantum effects as an (emergent) epiphenomenon, a secondary effect or byproduct that arises vis-à-vis quantized systems and does not stand separate from or independent of them.

In this view, distances are a matter of disentanglement and gradual: two events such as detector clicks are "apart" if their corresponding states are (for all practical purposes) factorizable and decomposable, and thus disentangled. Spacio-temporal separations and distances are to be understood more like the second law of thermodynamics [65]: they are not absolute, but relative to the (entanglement) means involved. This creates a "patchwork" of clocks and rulers, associated with the respective entanglements. Such emergent spacetime frames need not necessarily be consistent with one another, but rather form a mesh of spatial-temporal networks.

Most radically, what may be considered "far apart" in the old Kantian-Einsteinian framework maybe not be separated at all in the new scheme. For most practical pur- 
poses [92,93], the two notions of spatial-temporal distances may coincide. Because entanglement and "nonlocality" with respect to the old "absolute" theatrical framework of space-time (for all practical purposes) "happens locally" and-again according to the Ancien Régime in terms of Kantian-Einsteinian space-time frames-not "far away".

This radical departure from the Kant-Einsteinian framework of space-time by emergence from entanglement has been discussed in entanglement-induced gravity [94-101]. See also Ref. [102] for another approach to emergent space-time. This research program is a new and active area of research.

A lot of questions arise immediately. One issue that needs to be addressed is that of the finite speed of light, as compared to instantaneous entanglement: can some finite speed of information transfer be derived from an infinite property? One Ansatz is given in Ref. [103]. What is (inertial) motion, and the type of kinematics resulting from entanglement? Entanglement swapping comes to mind immediately, but this lacks any notion of inertia. Indeed, we might be tempted to speculate that the absence of inertia, rather than being a problematic feature, might be an advantage, suggesting possibilities of inertialess motion [104], and motion beyond the relativistic speed limit. It might not appear too unreasonable to speculate, that, if entanglement swapping takes place instantaneously, so maybe motion or signaling in space and time, even despite the following discussion.

\subsection{Peaceful Coexistence}

The argument stated by Einstein in his letter [84-86] to Schrödinger quoted earlier amounts to the aforementioned separation principle: measurement of a subsystem $A$ of $(A B)$ cannot alter the state of the subsystem $B$; in particular, not if the two subsystems are spatially separated. As noted earlier, Einstein attacked quantum mechanics for failing this principle for entangled multi-partite states. However, as our approach considers the emergence of space-time as secondary to quantization, rather than questioning the validity of quantum mechanics, we might as well respond with an "upside-down" question: why not? Why is space-time not challenged by these issues? To answer such questions, it might be prudent to compare a similar classical EPR-type configuration with classical and more general resources. We can imagine at least two scenarios:

(i) Value definiteness of the individual constituents $A$ and $B$ and the fixing of their respective local shares at creation point: for this scenario, Peres gave a most insightful analysis [105]. Classical "singlet" states (e.g., obtained by the preservation of angular momentum) may exhibit certain (dis-)similar behaviors as compared to the quantum case. Classically, the joint system $(A B)$ "carries" some "common share"—e.g., a hidden parameter such as the opposite angular momentum pseudovectors of the particles [106-108] along one and the same direction. These angular momentum pseudovectors are fixed and value definite for both parties or subsystems $A$ and $B$ already after their interaction. Therefore, the local information can in principle be used to produce local "copies" or "clones" of $A$ and $B$. This is consistent with relativity theory because those shares remain fixed after their creation, so that whatever manipulation happens on one side does not alter the respective state or share on the other side.

(ii) Value indefiniteness of the individual constituents $A$ and $B$, but the fixing of their respective global shares at creation point: This may for instance be achieved by assuming a global value definite share or state of $(A B)$; and yet by not allowing or "granting" definite states to the individual constituents $A$ and $B$. Therefore, any attempt to copy them fails because of the absence of value definiteness. Quantum mechanics "guarantees" or realizes such a scenario by demanding that any entangled quantized pair $(A B)$ exhibits a relational encoding. The states of the individual constituents $A$ and $B$ are not value definite: they lack "definiteness" or "memory" or information about individual properties of its constituents—the value definiteness "resides" in the relational (not the individual), holistic, global, "collective" properties among the constituents [59]. If such individual properties are "enforced" upon the constituents 
through measurement, they react with a context translation which, through nesting, introduces stochasticity because of the many degrees of freedom introduced from the "outside" environment. As a result, one obtains outcome independence, although one still obtains parameter dependence; but the latter is only "recoverable" after the outcomes from both sides are compared [109,110]; locality prevails [111,112].

Per se, both scenarios could be extended to any type of two-partite expectation functions, which need not be linear as in the classical case, but can take on any functional form; in particular, also the quantum "stronger"-than-classical, nonlinear (trigonometric because of the projective character of the quantum probabilities) form. Indeed, by the same argument expectations and correlations might be even "stronger" than classical and quantum ones [108,113-115] without violating Einstein locality.

Some argue that random outcomes "save" quantum mechanics from violating relativistic causality. Because if it were possible to somehow use the relational encoding of entangled inseparable states, either by duplicating nonorthogonal states [116], or by stimulated emmission [117], then $B$ could infer information on $A$ 's settings even before knowing $A^{\prime}$ 's outcome post factum, posterior, and in retrospect (after combining the knowledge of both outcomes). The random outcomes on $A$ 's side assure that $B$ cannot know what happens at the former side. This argument can be extended to stronger-than-quantum correlations.

However, this kind of "peaceful coexistence" $[109,110]$ may also be seen as a characterization of the second scenario (ii) discussed earlier. In particular, if one is considering the "common share" accessible to $A$ and $B$ : it is, say, a pure entangled state of $(A B)$; more formally, it is an indecomposable vector. As it is not decomposable, there is no meaning associated with individual properties of $A$ and $B$. In this form, quantum entanglement defines spatio-temporal proximity, yet cannot produce any means of communication between the entangled parties: the "more entangled" the parties get, the "less individual" properties they carry. Their common share, such as indecomposable vectors, cannot give rise to any form of classical communication between the entangled parties as it is useless.

I, therefore, suggest that rather than speaking about a "peaceful coexistence" between relativity and quantum theory, we should speak of this no-signaling constraint as an unavoidable feature of emergent space-time from entanglement. The value-definiteness of the common indecomposable vector share of $(A B)$; that is, in a value indefiniteness of the individual states of $A$ and $B$ results in stochasticity if individuality is forced upon those subsystems; very much in the same way as stochasticity emerges (by context translation) from coherent superpositions or linear combinations of states, when measured "along with the detuned, twisted contexts"; as sketched earlier.

\section{Historic Perception of Randomness}

In what follows, randomness will be discussed in the historic context. This is important because of the lessons one could learn for the contemporary debate and perception of lawlessness and randomness. According to an influential narrative, the European Enlightenment developed as a courageous, thorough, and highly successful-the criterion of success is taken relative to and in terms of full-spectrum dominance compared to alternative worldviews grounded in esoteric thought-exorcism of transcendence; in particular, the rejection of law-defying miracles [118]; moreover, the empirical sciences "established natural laws" of regular, reliable tempo-spacial coincidences which appear to be trustworthy and therefore of great utility.

The denial of any direct breach or "rupture" of the laws of nature ([119,120], Sect. III, 10) has pushed the boundaries of conceivable transcendental real-time interventions, and, in particular, divine providence, to the fringe of "gaps" ([119,120], Sect. III, 12) in the laws of nature- indeterminate situations where applicable laws, and thus the Principle of Sufficient Reason [121], have not (yet?) been identified.

As effective as the formal [122] and natural sciences are in terms of utility, they turn out to be as means and context relative as any construct of thought: those imaginations of 
the human mind cannot deliver any "Archimedean point" or "ontological anchor" upon which an "objective reality" (whatever that is) can be based.

Means relativity of an entity such as an idea or a physical theory is the dependence (eg., validity, existence) of this entity on the means, conventions, or assumptions employed. Context relativity relates to whatever are the circumstances that form the setting for an event in terms of which it can be fully understood. Perhaps means and context relativity are equivalent notions, yet the emphasis lies on different aspects of a situation.)

Indeed, it is my idealistic [123-126] observation, or rather, stance or conviction, that all our physical narratives [127-129], doubles [130,131], images [132,133], and-more optimistically - representations [134] of what we experience as "Nature" are metaphysicalor at least amalgamated with metaphysical components-and ultimately can be denounced as being suspended in our free thought. Therefore, historically, we experience a succession of incongruent, incommensurable [135-140] scientific research programs [141,142]; a lineup which should make us humble when it comes to the mind-boggling effectiveness [122] of some of our formalisms in predicting, programming, manipulating, and instrumentalizing physical systems. The desperation, if not nihilism, that results from the deconstruction of long-held beliefs and narratives has been very vividly described by Schopenhauer [143], as well as through Nietzsche's Übermensch [144,145] and Camus' Sisyphe [146].

An obvious counter-response to such idealistic positions is to contend that physics is firmly grounded in empirical data drawn from observation of experimental outcomes. Support of theoretical physical models in the form of corroboration or falsification $[147,148]$ by empirical evidence [149] is indispensable. As an extreme demand, physical theory should strive to include only operational entities which are physically realizable in terms of achievable actions and measurements [150-154].

However, the history of science presents ample evidence that it has never been possible to resort to empirical evidence for the advancement or discrimination of theoretical models alone [137,141,142]. Indeed, as stated by Einstein [84] (reprinted as Letter 206 in [85], my translation), there is a metaphysical circularity because "the real difficulty lies in the fact that physics is a kind of metaphysics; Physics describes 'reality'. However, we do not know what 'reality' is; we only know it through the physical description!" Furthermore, although both the prediction and the willful reproduction of phenomena appears to be the cornerstone of current natural sciences, the "empirical evidence" relating to "scientific facts" is often indirect and fragile, deserving a nuanced and careful analysis $[155,156]$.

I shall offer three examples for the type of problems encountered in quantum mechanics; all three related to the occurrence of certain "clicks" of detectors. Arguably, the occurrence or non-occurrence of such a click is the most elementary, binary observable one could think of. However, while the (non)registration of detector clicks may be considered indisputable (for all practical purposes [93], and notwithstanding quantum erasures or haunted measurements [48-56]) the "meaning" of such clicks [157] remain open to a great variety of perceptions, interpretations, and understandings.

The first example is about measurements [158] of violations of classical locality with time-varying analyzers [159] if the periodic switching is synchronized with photon emmissions [160]. A second example is about a debate [161,162] on quantum teleportation [163,164]. A third example is about the contingencies [76] arising from counterfactual arguments of Hardy-type configurations [75,165]. These cases document well the different claims and aspects derived from single detector clicks, as perceived by different participating discussants.

Other aspects related to very general limits on symbolic representations need to be acknowledged. Any formalization of physical (in)determinism by (in)computability, and physical randomness as algorithmic incompressibility, and general induction [166-170] would require transfinite means not available [171] in this Universe [172-174]. This is because the associated formal proofs are blocked by the aforementioned Gödel-Turingtype incompleteness/incomputability results. 
Therefore, one cannot expect that the formal and natural sciences offer absolute corroboration of any type of semantic statements. All they allow is the systematic exploitation of syntax and narratives which are true relative to the chosen means and purposes.

In what follows, we shall first discuss what general options of randomness can be imagined; and then proceed with a discussion of their concrete physical modi operandi.

\subsection{Bowler Type Scenario of a Clockwork Universe}

In what follows, "god" or "deity" is understood as an entity creating existence; a sort of "programmer of the Universe." The assumption of a "clockwork universe" — that is, "stuff" such as matter, energy, together with its assorted evolution laws which are uniformly valid and unique (leaving no room for alternatives) - entails a "bowler"-type situation. The Principle of Sufficient Reason [121] rules; nothing occurs without a "reason" or "cause". Once this universe is created ex nihilo and put into motion there is no further or additional interference with it; as all necessary and sufficient conditions exist to determine its evolution uniquely and completely from a "previous" state into a "later" one. In such a scenario free will appears to be illusory and subjectively, as per assumption choices are merely fictitious and delusional.

\subsubsection{How Could Physics Facilitate and Support Such a View?}

Here are some arguments that may be put forward in favor of a bowler-type clockwork universe:

(i) The description of a unique physical state as a function of some operational physical quantity such as time-indeed, the very notion of a total function (as opposed to partiality [77]), Laplace's demon, causal [175] determinism, and the Principle of Sufficient Reason are scientific tropes and schemes signifying clockwork universes. They were widely held in pre-statistical physics and quantum areas until around fin de siècle.

In ordinary differential equations of classical continuum mechanics and classical electrodynamics, the semantic notion of "determinism" is formalized by the uniqueness of the solutions, which are guaranteed by a Lipschitz continuity condition ([91], Chapter 17).

(ii) The quantum state evolution is postulated to be unique and deterministic. Formally this is represented by a unitary transformation, that is, a generalized rotation mapping one orthonormal basis into another one. Such a state evolution is one-to-one and thus reversible and unique. However, if the preparation context differs from the measurement context, the quantum state does not identify outcomes uniquely, thereby allowing one particular kind of quantum indeterminacy. However, in general —in the case of coherent superposition or mixed states-the quantum state is not operationally accessible. Therefore this sort of quantum determinacy cannot be given any direct empirical meaning.

(iii) Deterministic chaos is characterized by a unique initial value-a "seed" supposed to be taken from the mathematical continuum and thus incomputable and even random with probability one-whose information or digits are "revealed" by some suitable deterministic temporal evolution. (Idealized randomness of an infinite string is taken to be algorithmically incompressible [20].) To be suitable a temporal evolution needs to be very sensitive to changes of initial seeds such that very small fluctuations may produce very large effects. This is like Maxwell's gap scenario discussed later. Like quantum evolution, deterministic chaos might be considered both an argument for and against classical determinism: because the assumption of the continuum renders almost all seeds formally random [20], thereby passing all statistical tests of randomness; in particular an "elementary" test such as Borel normality, certifying that all sequences of arbitrary length occur with the expected frequency, but also much stronger ones. Unfortunately, Borel normality is no guarantee of randomness because very regular sequences, for instance, the Champernowne constant [176] $C_{10}$ in base 10 
is just the sequence obtained by concatenating successive numbers (encoded in base 10), turn out to be normal.

In this respect, classical machinery designed to use extreme sensitivities of the temporal evolution to the initial seed, such as the Athenian [177] $\kappa \lambda \eta \rho \omega \tau \eta \rho\llcorner o v$ (kleroterion), for all practical purposes is not inferior to a quantum oracle for randomness, such as QUANTIS [18], based on the "evangelical" belief of irreducible quantum randomness [31].

(iv) In system science or virtual physics, this modus could be referred to as a very restricted virtual reality, computational gaming environment, or simulation [178-181] (aka simulacrum), whereby it is assumed that there is no interference from "the outside" ( $a k a$ beyond): the respective universe is hermetic. No participation is possible; only passive (without interference) observation.

\subsubsection{How Could Physics Contradict Such a View?}

Here are some arguments that may be put forward against a bowler-type clockwork universe:

(i) Classical gaps are characterized by instabilities at singular points, such that very small fluctuations may produce very large effects. To quote Maxwell ([182], pp. 211,212), "for example, the rock loosed by frost and balanced on a singular point of the mountainside, the little spark which kindles the great forest ... At these points, influences whose physical magnitude is too small to be taken account of by a finite being, may produce results of the greatest importance".

(ii) In some physical situations the Lipschitz continuity is violated, yielding no unique solutions. The Norton dome $[183,184]$ is a contemporary example of such a situation.

(iii) Spontaneous symmetry breaking, a physical (re)source of non-uniqueness, is a spontaneous process by which a physical system in a symmetric state ends up in an asymmetric state. This is facilitated by some appropriate "Mexican hat" potential, not dissimilar to Norton's dome or Maxwell's ([182], pp. 211,212) "rock loosed by frost and balanced on a singular point" mentioned earlier.

In particle physics, the Higgs mechanism, the spontaneous symmetry breaking of gauge symmetries, plays an important role in the origin of particle masses in the standard model of particle physics. All of these ruptures or breaches of uniqueness depend on the assumptions and models involved.

(iv) Quantum indeterminacy, in particular, complementarity, contextuality (aka value indefiniteness), and aspects (such as the exact decay time) of the occurrence of certain single events are postulated to signify indeterminism.

Because of both formal and empirical reasons, these scenarios might not be interrelated and not separate: for instance, one might suspect that Maxwell's instabilities at singular points could be formalized by "Mexican hat" type potentials discussed in spontaneous symmetry breaking, or by ordinary differential equations yielding Norton dome-type configurations. One might even speculate that all violations of Lipschitz continuity amount to some kind of symmetry breaking.

Empirically, one might argue that, for all practical purposes [93], Maxwell's scenario and Norton dome-type configurations (related to violations of Lipschitz continuity) or spontaneous symmetry breaking, never "actually" happen. Because for all practical purposes a rock loosed by frost is never (with probability zero) symmetrically balanced at a singular point; rather the position of its center of gravity will fluctuate around the tip, thereby spoiling symmetry. Furthermore, one may argue that, due to (vacuum) fluctuations, singular points make no operational sense; they are (over)idealized concepts invented by the human mind for mere convenience. In particular, microscopic quantum zero-point fluctuations, and thermal fluctuations [185] ultimately spoil symmetries. Therefore, all such exploitations of such singularities might confuse epistemic convenience with an ontology that has no physical, operational grounds. 


\subsection{Scenario of a Stochastic, Disorganized Universe}

The "converse" of a Laplacean determinism governed by a unique state evolution "tied to" previous states, as mentioned in the previous section, is one in which any given state is independent of the respective previous (and future) states. (Two events $A$ and $B$ are statistically independent if their joint probability $P(A \cap B)$ can be written as the product of their single probabilities $P(A)$ and $P(B)$; that is, $P(A \cap B)=P(A) P(B)$. It turns out that this results in a journey down a rabbit hole, as the concept of probability is a nontrivial one [186].) In such a most extreme scenario among many conceivable degrees of stochasticity the universe is "completely" stochastic and disorganized on the most fundamental level. For the embedded observer's intrinsic perspective, due to irreducible contingency and chance, it appears as if such a world is constantly created anew by throwing some sort of dice.

This may be considered an extreme form of creatio continua. However, extrinsicallythat is, from an external, extrinsic, perspective-this may be considered creatio ex nihilo as no active, real-time participation is assumed. Indeed, one may speculate that if the temporal ordering of events (and causality) turns out to be epistemic - an intrinsically emerging concept/observable of (self-)cognition/observation - then any differentiation based on temporal creation-such as creatio continua versus ex nihilo-turns out to be a "red herring." Alas, without granting "time" some ontology, also differentiation between a "bowling" or "curling" god collapse.

Whether and how some sort of structural continuity of existence can emerge and be maintained under such circumstances is a fascinating question. As in such a scenario space and time, as much as notions of causality and the laws, are emergent concepts, continuity might emerge with them.

Indeed, one might speculate that "the laws" are some sort of expressions of chaos, the formation of matter and genes are expressions of these laws, the individuals carrying those genes are expressions thereof [187], and that the ideas about the world are expressions of these individuals. In that transitive way, the Universe contemplates itself through our ideas-ideas such as religion, mathematics, ethics, and so on. (This is not dissimilar to the impossible choice not to communicate [188].)

Contemporary physics supports such a view in postulating that many elementary events-such as the spontaneous or stimulated emission of photons-occur acausally, irreducibly pure, and simple [31,189]. Indeed, both classical statistical physics at finite resolution, and quantum mechanics, support such a view. (A Laplacian demon with unbounded resources might be able to determine future states from present ones with arbitrary precision.)

The Viennese fin de siècle physicist Exner [190,191], motivated by statistical physics and the radiation law [192], suggested that $([193]$, pp. 7,18) “. . laws do not exist in nature, those are only formulated by man, he makes use of it as a linguistic and computational aid and only wants to say that the processes in nature run as if matter, like a sentient being, would obey these laws. ... So we must understand all so-called exact laws only as average laws, which are not valid with absolute certainty, but with the higher probability the more individual processes they result from. All physical laws go back to molecular processes of random nature and from them follows the result according to the laws of probability calculus ...."

Even in totally "random" datasets, some sort of structure must necessarily emerge by the law of large numbers: for instance, if two dice are thrown sufficiently often, the number seven appears to be the most likely sum of their two faces. Modern arguments for the emergence of laws from chaos employ, among other methods [194-201], Ramsey theory, for structure formation and structural continuity through spurious correlations [202]. It is irrelevant whether these events occur "absolutely randomly"-indeed, as has been pointed out earlier, on an individual level and with finitistic means, "absolute randomness" appears to be a vacuous concept. 


\subsection{The Intermediate Curler Case}

Intuitively, the curler case [203] is one in which the natural laws-whatever their form and origin - predominate, but there are situations in which such laws do not exist, or if laws exist, they are violated. The first "weak" case of indeterminism can be realized by gaps.

As mentioned earlier ([119,120], Sect. III, 10) "stronger" forms of curling involve a "rupture" of the laws of nature, as they are in direct violations of those laws as mentioned in Voltaire's Philosophical Dictionary ([204], Chapter 330). Although nobody can a priori exclude such latter cases we shall henceforth stick with Hume's attitude towards miracles ([156], Section X) and neglect them.

Theologically, this could be perceived as a mild form of creatio continua (cf. my earlier remarks on creatio continua in Section 2.2): god has created laws that are not violated, but god also left "some room" to communicate via gaps.

A "god of the gaps" has been rephrased in many ways. This concept is also quite popular since, on the one hand, the obvious regularities of experience and life express correlations or laws which appear evident: the daily cycle of the sun, the yearly cycle of the seasons, life, death; apples and other stuff falling down and not up, and so on. So denial of regularities appears futile. On the other hand, humans experience fate and uncontrollable circumstances quite often. In a similar reaction, the primitive mind (re)interpreted such "evidence" as god's signal.

As more and more "fateful" behaviors became "understood" and even controllablethink of medical conditions and also volcanic eruptions, floods or weather phenomena such as lightning and thunder-it is not unreasonable to speculate that, maybe, eventually, there will be no such gaps left-in which case one recovers the bowler, ex nihilo, scenario. Alternatively some "pure" gaps in the causal fabric of our universe might "turn out" that is, relative to the assumptions and means employed - to be irreducible and final: those gaps cannot be eliminated and might remain forever. In secular terms, this could be suspected to signify irreducible indeterminism or randomness [31]. However, there exist other, possibly transcendental, interpretations involving intentionality across gaps.

That these latter scenarios are not purely speculative can be demonstrated by an interactive gaming scenario: If one is considering an interactive virtual reality environment $[205,206]$ one usually assumes that the virtual reality is "sustained" or "supported" by a computational process "running" on some kind of computer whose physical characteristics are not directly related to the simulacrum. To be feasible and nonmonotonic it can be assumed without loss of generality that both the universe in which the simulation is implemented and the simulated universe are capable of universal computation in the sense of Chuch-Turing. To be interactive the two universes need to be intertwined and connected by some sort of (bidirectional) gap through which information flows in both "directions".

This could result in a sort of dialogue between those realms-a "backflow" from the simulacrum to the universe in which the simulation takes place-such that the former simulacrum performs "empirical studies" on the latter, thereby fully and actively participating in it. In this very speculative scenario, "transcendence becomes immanence." Think of evolving artificial intelligence in a computer simulation becoming aware of its situation and asking online players questions about its situation and the general setup. However, as symmetric as an exchange through the interface may appear, it is asymmetric in one aspect: whereas the simulacrum cannot exist without the world in which the simulation takes place the latter can exist without the former.

For an intrinsic [207] observer embedded [178] in the virtual environment and bound by its operational means the capacity to send an arbitrary signal through the interfacefrom the simulating universe (aka "the beyond") to the simulacrum-can only be realized by a gap. Because without a gap, the signal must remain immanent; that is, it reduces to either lawful or chaotic behavior.

Gaps potentially allow some "transcendental" exchange of signals but do not necessarily imply such a conversation or dialogue. Therefore, gaps are a necessary but not a 
sufficient condition for transcendence- -just because gaps have been located does not imply the existence of "active" transcendental entities.

From a theological perspective, gaps can realize individual (human) soul/mind-body dualism [208], and also divine providence ([119,120], Sect. III, 9-16).

How does physics support gaps? Can physics rule them out? The following is an update and extension of Frank's discussion on physical gaps.

(i) As has been mentioned earlier, in the classical domain of ordinary differential equations some breach of the Lipschitz continuity condition ([91], Chapter 17) could cause nonunique solutions. Often such types of gaps are identified with instabilities at their singular points ([182], pp. 211,212, [119,120], Sect. III, 13).

(ii) As has also been discussed earlier, quantum complementarity, and, as an extension thereof, quantum contextuality (aka value indefiniteness) can be interpreted as the impossibility to co-represent $[22,106,209]$ certain (even finite) sets of-necessarily counterfactual because they are complementary-quantum observables, relative to the assumptions. (One assumption entering those proofs are the (context) independence of outcomes of measurements for "intertwine" observables occurring in more than one context. For reasons of being able to intertwine contexts formalized by orthonormal bases this can only happen in vector spaces of dimension higher than two.) This is problematic as the corresponding experimental protocols ("prepare a pure state and measure a different one") seem to suggest that they "reveal" some pre-existing property-indicated by the (non)occurrence of a detector click. This could be misleading, as the respective click might either be subject to debate and interpretation or merely signify the capacity of the measurement apparatus to "translate an improper question;" introducing stochastic noise [63]. (A debate [161,162] on the alleged " $a$ posteriori teleportation" is an example for such a nonunique semantic perception of syntactically undisputed detector clicks.) This appears to be related to notorious inconsistencies in quantum physics proper $[25,38,39,47,210]$ due to the assumption of irreversible quantum measurements.

(iii) Aspects of certain individual, single events in quantized systems such as the time of emission or absorption of single quanta of light, are postulated to be indeterministic.

\section{The (Un)known (Un)knowns}

The relativity of the considerations on the respective assumptions and means invested or taken for granted results in an echo-chamber of sorts: whatever one puts in one gets out. As mentioned earlier there is no "firm (meta)physical ground," no undisputable "Archimedean ontological anchor" upon which such speculations can be based. Furthermore, the tendency of the mind to rationalize, project [211-213], and empathically embrace opinions that are favorable to one's ego-investments increases delusions about particular beliefs and corroborations thereof even further.

At this point, the reader might get frustrated: a negative message (akin to a negative theology) has been delivered. Alas, unfortunately, this is all that can be safely stated. One positive side effect might be the abandoning of what the Vienna Circle (in a Humean tradition) called "meaningless pseudo-statements" [214-216] targeting a particular hocuspocus, abracadabra delusional (thought) rituals delivered by sophistic philosophers and an orthodox clergy. However, one has to be very careful not to "throw the baby out with the bathwater." Shortly after these bold rejections of metaphysical entities, it turned out that their program based on empirical evidence and formal logic proposed could not be carried out as completely as desired [217-223].

Therefore, we should accept the sobering fact that there is certainty only in our uncertainty. This has been expressed by many insightful individuals of many philosophical traditions and religions and at various times. Aurelius Augustinus, for instance, writes ([224], Book XI, chapter 25.32), "Do I perhaps not know how to express what I do know? Woe is me: I do not even know what it is I do not know!" 


\section{Summary}

Quantum randomness appears epistemic: identical pre- and post-selected states and observables yield definite outcomes because the vector or projection operator shares are identical. If there is a mismatch between preparation and measurement, then the measurement apparatus, as part of the environment, may "contribute" to the respective outcomes by context translation. Therefore, randomness extracted from coherent superpositions or linear combinations of the quantum state might be based on the complexity of the environment rather than on the intrinsic, ontologic "oracle" nature of the state. "Objectification"-the emergence of a property which the original state is not encoded in-is associated with this influx of information from the environment.

This readily extends into entanglement: relationaly encoded quantum shares (that can be pure entangled states represented by inseparable vectors) will not be able to render individual value definiteness of its constituents that is necessary for communication between those constituents. This relates to the concept of emergent space-time from separation through nonentanglement, and inseparability by entanglement.

In the second part of the paper, a wealth of historic resources on random physical outcomes has been reviewed. The emphasis has been on the "evangelical" side of the perception of value indefiniteness, as it has emerged historically.

Funding: This research was funded in whole, or in part, by the Austrian Science Fund (FWF), Project No. I 4579-N. For the purpose of open access, the author has applied a CC BY public copyright license to any Author Accepted Manuscript version arising from this submission.

Acknowledgments: I kindly acknowledge discussions with and suggestions by Cristian Calude, Kelly James Clark, Philippe Grangier, Silvia Jonas, Jeffrey Koperski, Irem Kurtsal, Emil Salim, Mohammad Hadi Shekarriz, and Noson S. Yanofsky. All misconceptions and errors are mine.

Conflicts of Interest: The author declares no conflict of interest. The funders had no role in the design of the study; in the collection, analyses, or interpretation of data; in the writing of the manuscript, or in the decision to publish the results.

\section{References}

1. Feynman, R.P. Simulating physics with computers. Int. J. Theor. Phys. 1982, 21, 467-488. [CrossRef]

2. Deutsch, D. Quantum theory, the Church-Turing principle and the universal quantum computer. Proc. R. Soc. Lond. Ser. A 1985, 400, 97-117. [CrossRef]

3. Deutsch, D.; Jozsa, R. Rapid solution of problems by quantum computation. Proc. R. Soc. 1992, 439, 553-558. [CrossRef]

4. Nielsen, M.A.; Chuang, I.L. Quantum Computation and Quantum Information; Cambridge University Press: Cambridge, UK, 2010. [CrossRef]

5. Mermin, D.N. Quantum Computer Science; Cambridge University Press: Cambridge, UK, 2007. [CrossRef]

6. Svozil, K. Quantum hocus-pocus. Ethics Sci. Environ. Politics 2016, 16, 25-30. [CrossRef]

7. Calude, C.S.; Calude, E. The Road to Quantum Computational Supremacy. In From Analysis to Visualization, Proceedings of the JBCC 2017: Jonathan M. Borwein Commemorative Conference, Newcastle, NSW, Australia, 25-29 September 2017; Springer: Cham, Switzerland, 2020; Volume 313, pp. 349-367. [CrossRef]

8. Um, M.; Zhang, X.; Zhang, J.; Wang, Y.; Yangchao, S.; Deng, D.L.; Duan, L.M.; Kim, K. Experimental Certification of Random Numbers via Quantum Contextuality. Sci. Rep. 2013, 3, 1627. [CrossRef] [PubMed]

9. Svozil, K. The quantum coin toss-Testing microphysical undecidability. Phys. Lett. A 1990, 143, 433-437. [CrossRef]

10. Jennewein, T.; Achleitner, U.; Weihs, G.; Weinfurter, H.; Zeilinger, A. A Fast and Compact Quantum Random Number Generator. Rev. Sci. Instrum. 2000, 71, 1675-1680. [CrossRef]

11. Stefanov, A.; Gisin, N.; Guinnard, O.; Guinnard, L.; Zbinden, H. Optical quantum random number generator. J. Mod. Opt. 2000, 47, 595-598. [CrossRef]

12. Svozil, K. Three criteria for quantum random-number generators based on beam splitters. Phys. Rev. A 2009, 79, 054306. [CrossRef]

13. Fürst, M.; Weier, H.; Nauerth, S.; Marangon, D.G.; Kurtsiefer, C.; Weinfurter, H. High speed optical quantum random number generation. Opt. Express 2010, 18, 13029-13037. [CrossRef]

14. Calude, C.S.; Dinneen, M.J.; Dumitrescu, M.; Svozil, K. Experimental evidence of quantum randomness incomputability. Phys. Rev. A 2010, 82, 022102. [CrossRef]

15. Abbott, A.A.; Calude, C.S.; Svozil, K. A quantum random number generator certified by value indefiniteness. Math. Struct. Comput. Sci. 2014, 24, e240303. [CrossRef] 
16. Pironio, S.; Acín, A.; Massar, S.; Boyer de la Giroday, A.; Matsukevich, D.N.; Maunz, P.; Olmschenk, S.; Hayes, D.; Luo, L.; Manning, T.A.; et al. Random numbers certified by Bell's theorem. Nature 2010, 464, 1021-1024. [CrossRef] [PubMed]

17. Abbott, A.A.; Calude, C.S.; Dinneen, M.J.; Huang, N. Experimentally probing the algorithmic randomness and incomputability of quantum randomness. Phys. Scr. 2019, 94, 045103. [CrossRef]

18. ID Quantique. QUANTIS. Quantum Number Generator; ID Quantique: Geneva, Switzerland, 2001-2010. Available online: https:/ / www.idquantique.com/random-number-generation/products / quantis-random-number-generator/ (accessed on 8 September 2019).

19. Bennett, C.H.; Brassard, G. Quantum Cryptography: Public key distribution and coin tossing. In Proceedings of the IEEE International Conference on Computers, Systems, and Signal Processing, Bangalore, India, 10-12 December 1984; pp. 175-179.

20. Martin-Löf, P. The definition of random sequences. Inf. Control. 1966, 9, 602-619. [CrossRef]

21. Abbott, A.A.; Calude, C.S.; Svozil, K. Value-indefinite observables are almost everywhere. Phys. Rev. A 2014, 89, 032109. [CrossRef]

22. Abbott, A.A.; Calude, C.S.; Svozil, K. A variant of the Kochen-Specker theorem localising value indefiniteness. J. Math. Phys. 2015, 56, 102201. [CrossRef]

23. Abbott, A.A.; Calude, C.S.; Conder, J.; Svozil, K. Strong Kochen-Specker theorem and incomputability of quantum randomness. Phys. Rev. A 2012, 86, 062109. [CrossRef]

24. Bera, M.N.; Acín, A.; Kuś, M.; Mitchell, M.W.; Lewenstein, M. Randomness in quantum mechanics: Philosophy, physics and technology. Rep. Prog. Phys. 2017, 80, 124001. [CrossRef]

25. Everett, H., III. 'Relative State' Formulation of Quantum Mechanics. Rev. Mod. Phys. 1957, 29, 454-462. [CrossRef]

26. Vaidman, L. Quantum theory and determinism. Quantum Stud. Math. Found. 2014, 1, 5-38. [CrossRef]

27. Svozil, K. "Haunted" quantum contextuality. arXiv 1999, arXiv:9907015.

28. Svozil, K. Proposed direct test of a certain type of noncontextuality in quantum mechanics. Phys. Rev. A 2009, 80, 040102. [CrossRef]

29. Griffiths, R.B. What quantum measurements measure. Phys. Rev. A 2017, 96, 032110. [CrossRef]

30. Griffiths, R.B. Quantum measurements and contextuality. Philos. Trans. R. Soc. A 2019, 377, 20190033. [CrossRef] [PubMed]

31. Zeilinger, A. The message of the quantum. Nature 2005, 438, 743. [CrossRef]

32. Von Neumann, J. Various Techniques Used in Connection With Random Digits. In Monte Carlo Method; National Bureau of Standards Applied Mathematics Series; Householder, A.S., Forsythe, G.E., Germond, H.H., Eds.; US Government Printing Office: Washington, DC, USA, 1951; Volume 12, Chapter 13, pp. 36-38.

33. Von Neumann, J. John von Neumann: Collected Works. Volume V: Design of Computers, Theory of Automata and Numerical Analysis; Pergamon: New York, NY, USA, 1963.

34. Abbott, A.A.; Calude, C.S. Von Neumann normalisation of a quantum random number generator. Computability 2012, 1, 59-83. [CrossRef]

35. Clauser, J.F. Early History of Bell's Theorem Theory and Experiment. In Foundations of Quantum Mechanics; World Scientific: Singapore, 1992; pp. 168-174. [CrossRef]

36. Clauser, J.F. Early History of Bell's Theorem. In Quantum (Un)speakables: From Bell to Quantum Information; Bertlmann, R., Zeilinger, A., Eds.; Springer: Berlin/Heidelberg, Germany, 2002; pp. 61-96. [CrossRef]

37. Schwinger, J. Unitary operators bases. Proc. Natl. Acad. Sci. USA 1960, 46, 570-579. [CrossRef]

38. Von Neumann, J. Mathematische Grundlagen der Quantenmechanik, 2nd ed.; Springer: Berlin/Heidelberg, Germany, 1996. (In German) [CrossRef]

39. Von Neumann, J. Mathematical Foundations of Quantum Mechanics; Princeton University Press: Princeton, NJ, USA, 1955. (In English)

40. Schrödinger, E. Die gegenwärtige Situation in der Quantenmechanik. Naturwissenschaften 1935, 23, 807-812. [CrossRef]

41. Schrödinger, E. Die gegenwärtige Situation in der Quantenmechanik. Naturwissenschaften 1935, 23, 823-828. [CrossRef]

42. Schrödinger, E. Die gegenwärtige Situation in der Quantenmechanik. Naturwissenschaften 1935, 23, 844-849. [CrossRef]

43. London, F.; Bauer, E. La Theorie de L'observation en Mécanique Quantique; No. 775 of Actualités Scientifiques et Industrielles: Exposés de Physique Générale, Publiés Sous la Direction de Paul Langevin; Hermann: Paris, France, 1939. (In French)

44. London, F.; Bauer, E. The Theory of Observation in Quantum Mechanics. In Quantum Theory and Measurement; Princeton University Press: Princeton, NJ, USA, 1983; pp. 217-259. (In English)

45. Barrett, J.A. Everett's pure wave mechanics and the notion of worlds. Eur. J. Philos. Sci. 2011, 1, 277-302. [CrossRef]

46. Everett, H., III. The Theory of the Universal Wave Function. In The Everett Interpretation of Quantum Mechanics: Collected Works 1955-1980 with Commentary; Barrett, J.A., Byrne, P., Eds.; Princeton University Press: Princeton, NJ, USA, $2012 ;$ pp. $72-172$.

47. Wigner, E.P. Remarks on the mind-body question. In The Scientist Speculates; Good, I.J., Ed.; Springer: Berlin/Heidelberg, Germany, 1995; pp. 284-302. [CrossRef]

48. Peres, A. Can we undo quantum measurements? Phys. Rev. D 1980, 22, 879-883. [CrossRef]

49. Scully, M.O.; Drühl, K. Quantum eraser: A proposed photon correlation experiment concerning observation and "delayed choice" in quantum mechanics. Phys. Rev. A 1982, 25, 2208-2213. [CrossRef]

50. Greenberger, D.M.; YaSin, A. "Haunted" measurements in quantum theory. Found. Phys. 1989, 19, 679-704. [CrossRef]

51. Scully, M.O.; Englert, B.G.; Walther, H. Quantum optical tests of complementarity. Nature 1991, 351, 111-116. [CrossRef] 
52. Zajonc, A.G.; Wang, L.J.; Zou, X.Y.; Mandel, L. Quantum eraser. Nature 1991, 353, 507-508. [CrossRef]

53. Kwiat, P.G.; Steinberg, A.M.; Chiao, R.Y. Observation of a "quantum eraser:" A revival of coherence in a two-photon interference experiment. Phys. Rev. A 1992, 45, 7729-7739. [CrossRef]

54. Pfau, T.; Spälter, S.; Kurtsiefer, C.; Ekstrom, C.R.; Mlynek, J. Loss of Spatial Coherence by a Single Spontaneous Emission. Phys. Rev. Lett. 1994, 73, 1223-1226. [CrossRef]

55. Chapman, M.S.; Hammond, T.D.; Lenef, A.; Schmiedmayer, J.; Rubenstein, R.A.; Smith, E.; Pritchard, D.E. Photon Scattering from Atoms in an Atom Interferometer: Coherence Lost and Regained. Phys. Rev. Lett. 1995, 75, 3783-3787. [CrossRef]

56. Herzog, T.J.; Kwiat, P.G.; Weinfurter, H.; Zeilinger, A. Complementarity and the quantum eraser. Phys. Rev. Lett. 1995, 75, 3034-3037. [CrossRef]

57. Englert, B.G.; Schwinger, J.; Scully, M.O. Is spin coherence like Humpty-Dumpty? I. Simplified treatment. Found. Phys. 1988, 18, 1045-1056. [CrossRef]

58. Schwinger, J.; Scully, M.O.; Englert, B.G. Is spin coherence like Humpty-Dumpty? II. General theory. Z. Für Phys. Atoms Mol. Clust. 1988, 10, 135-144. [CrossRef]

59. Zeilinger, A. A Foundational Principle for Quantum Mechanics. Found. Phys. 1999, 29, 631-643. [CrossRef]

60. Yanofsky, N.S. The Mind and the Limitations of Physics; Spider Science: Brooklyn, NY, USA, 2019.

61. Gallois, A. Identity Over Time. In The Stanford Encyclopedia of Philosophy; Zalta, E.N., Ed.; Metaphysics Research Lab, Stanford University: Stanford, CA, USA, 2016.

62. Gallois, A. Occasions of Identity: A Study in the Metaphysics of Persistence, Change, and Sameness; Bantam Books: New York, NY, USA, 2011,

63. Svozil, K. Quantum information via state partitions and the context translation principle. J. Mod. Opt. 2004, 51, 811-819. [CrossRef]

64. Svozil, K. Unscrambling the Quantum Omelette. Int. J. Theor. Phys. 2014, 53, 3648-3657. [CrossRef]

65. Myrvold, W.C. Statistical mechanics and thermodynamics: A Maxwellian view. Stud. Hist. Philos. Sci. Part B 2011, 42, 237-243. [CrossRef]

66. Bohr, N. Discussion with Einstein on epistemological problems in atomic physics. In Albert Einstein: Philosopher-Scientist; Schilpp, P.A., Ed.; The Library of Living Philosophers: Evanston, IL, USA, 1949; pp. 200-241. [CrossRef]

67. Foti, C.; Heinosaari, T.; Maniscalco, S.; Verrucchi, P. Whenever a quantum environment emerges as a classical system, it behaves like a measuring apparatus. Quantum 2019, 3, 179. [CrossRef]

68. Glauber, R.J. Amplifiers, Attenuators and Schrödingers Cat. In Quantum Theory of Optical Coherence; Wiley-VCH Verlag GmbH \& Co. KGaA: Weinheim, Germany, 2007; pp. 537-576. [CrossRef]

69. Glauber, R.J. Amplifiers, Attenuators, and Schrödinger's Cat. Ann. N. Y. Acad. Sci. 1986, 480, 336-372. [CrossRef]

70. Pitowsky, I. Infinite and finite Gleason's theorems and the logic of indeterminacy. J. Math. Phys. 1998, 39, 218-228. [CrossRef]

71. Svozil, K. New Forms of Quantum Value Indefiniteness Suggest That Incompatible Views on Contexts Are Epistemic. Entropy 2018, 20, 406. [CrossRef] [PubMed]

72. Specker, E. Die Logik nicht gleichzeitig entscheidbarer Aussagen. Dialectica 1960, 14, 239-246. [CrossRef]

73. Specker, E. Selecta; Birkhäuser Verlag: Basel, Switzerland, 1990. [CrossRef]

74. Svozil, K. Quantum Scholasticism: On Quantum Contexts, Counterfactuals, and the Absurdities of Quantum Omniscience. Inf. Sci. 2009, 179, 535-541. [CrossRef]

75. Cabello, A.; Portillo, J.R.; Solís, A.; Svozil, K. Minimal true-implies-false and true-implies-true sets of propositions in noncontextual hidden-variable theories. Phys. Rev. A 2018, 98, 012106. [CrossRef]

76. Svozil, K. Classical Predictions for Intertwined Quantum Observables Are Contingent and Thus, Inconclusive. Quantum Rep. 2020, 2, 278-292. [CrossRef]

77. Kleene, S.C. General recursive functions of natural numbers. Math. Ann. 1936, 112, 727-742. [CrossRef]

78. Brukner, Č.; Zeilinger, A. Operationally Invariant Information in Quantum Measurements. Phys. Rev. Lett. 1999, 83, 3354-3357. [CrossRef]

79. Brukner, Č.; Zeilinger, A. Malus' law and quantum information. Acta Phys. Slovaca 1999, 49, 647-652. Available online: https://www.univie.ac.at/qfp/publications3/pdffiles/1999-08.pdf (accessed on 8 September 2019).

80. Grangier, P.; Auffèves, A. What is quantum in quantum randomness? Philos. Trans. R. Soc. A Math. Phys. Eng. Sci. 2018, 376, 20170322. [CrossRef]

81. von Neumann, J. On infinite direct products. Compositio Math. 1939, 6, 1-77. Available online: http://www.numdam.org/item/ CM_1939_6_1_0/ (accessed on 8 September 2019).

82. Auffèves, A.; Grangier, P. A Generic Model for Quantum Measurements. Entropy 2019, 21, 904. [CrossRef]

83. Calude, C.S.; Dinneen, M.J. Exact Approximations of Omega Numbers. Int. J. Bifurc. Chaos 2007, 17, 1937-1954. [CrossRef]

84. Einstein, A. Letter to Schrödinger. Old Lyme, dated 19.6.35, Einstein Archives 22-047. Available online: https:// einsteinpapers. press.princeton.edu (accessed on 22 April 2021).

85. Von Meyenn, K. Eine Entdeckung von Ganz außerordentlicher Tragweite. Schrödingers Briefwechsel zur Wellenmechanik und Zum Katzenparadoxon; Springer: Berlin/Heidelberg, Germany, 2011. [CrossRef]

86. Howard, D. Einstein on locality and separability. Stud. Hist. Philos. Sci. Part A 1985, 16, 171-201. [CrossRef] 
87. Einstein, A.; Podolsky, B.; Rosen, N. Can quantum-mechanical description of physical reality be considered complete? Phys. Rev. 1935, 47, 777-780. [CrossRef]

88. Schrödinger, E. Probability relations between separated systems. Math. Proc. Camb. Philos. Soc. 1936, 32, 446-452. [CrossRef]

89. Schrödinger, E. Discussion of Probability Relations between Separated Systems. Math. Proc. Camb. Philos. Soc. 1935, 31, 555-563. [CrossRef]

90. Svozil, K. A note on the statistical sampling aspect of delayed choice entanglement swapping. In Probing the Meaning of Quantum Mechanics; World Scientific: Singapore, 2018; pp. 1-9. [CrossRef]

91. Svozil, K. Physical (A)Causality; Fundamental Theories of Physics; Springer International Publishing: Berlin/Heidelberg, Germany, 2018; Volume 192. [CrossRef]

92. Bell, J.S. Against 'measurement'. Phys. Blätter 1992, 48, 267. [CrossRef]

93. Bell, J.S. Against 'measurement'. Phys. World 1990, 3, 33-41. [CrossRef]

94. Van Raamsdonk, M. Building up spacetime with quantum entanglement. Gen. Relativ. Gravit. 2010, 42, 2323-2329. [CrossRef]

95. Van Raamsdonk, M. Building up spacetime with quantum entanglement. Int. J. Mod. Phys. D 2010, 19, 2429-2435. [CrossRef]

96. Faulkner, T.; Guica, M.; Hartman, T.; Myers, R.C.; Raamsdonk, M.V. Gravitation from entanglement in holographic CFTs. J. High Energy Phys. 2014, 2014. [CrossRef]

97. Swingle, B.; Van Raamsdonk, M. Universality of Gravity from Entanglement. arXiv 2014, arXiv:1405.2933.

98. Jacobson, T. Entanglement Equilibrium and the Einstein Equation. Phys. Rev. Lett. 2016, 116, 201101. [CrossRef]

99. Cao, C.; Carroll, S.M.; Michalakis, S. Space from Hilbert space: Recovering geometry from bulk entanglement. Phys. Rev. D 2017, 95, 024031. [CrossRef]

100. Swingle, B. Spacetime from Entanglement. Annu. Rev. Condens. Matter Phys. 2018, 9, 345-358. [CrossRef]

101. Musser, G. What Is Spacetime? Nature 2018, 557, S3-S6. [CrossRef]

102. Knuth, K.H.; Bahreyni, N. The Physics of Events: A Potential Foundation for Emergent Space-Time. arXiv 2012, arXiv:1209.0881.

103. Couch, J.; Eccles, S.; Nguyen, P.; Swingle, B.; Xu, S. Speed of quantum information spreading in chaotic systems. Phys. Rev. B 2020, 102, 045114. [CrossRef]

104. Knuth, K.H.; Powell, R.M.; Reali, P.A. Estimating Flight Characteristics of Anomalous Unidentified Aerial Vehicles. Entropy 2019, 21, 939. [CrossRef]

105. Peres, A. Unperformed experiments have no results. Am. J. Phys. 1978, 46, 745-747. [CrossRef]

106. Peres, A. Quantum Theory: Concepts and Methods; Kluwer Academic Publishers: Dordrecht, The Netherlands, 1993.

107. Toner, B.F.; Bacon, D. Communication Cost of Simulating Bell Correlations. Phys. Rev. Lett. 2003, 91, 187904. [CrossRef]

108. Svozil, K. Communication cost of breaking the Bell barrier. Phys. Rev. A 2005, 72, 050302. [CrossRef]

109. Shimony, A. Controllable and uncontrollable non-locality. In Proceedings of the International Symposium Foundations of Quantum Mechanics in the Light of New Technology; Kamefuchi, S., Gakkai, N.B., Eds.; Physical Society of Japan: Tokyo, Japan, 1984; pp. 225-230.

110. Shimony, A. Events and Processes in the Quantum World. In Quantum Concepts in Space and Time; Penrose, R., Isham, C.I., Eds.; Clarendon Press: Oxford, UK, 1986; pp. 182-203.

111. Griffiths, R.B. Quantum Locality. Found. Phys. 2010, 41, 705-733. [CrossRef]

112. Griffiths, R.B. Nonlocality claims are inconsistent with Hilbert-space quantum mechanics. Phys. Rev. A 2020, 101. [CrossRef]

113. Popescu, S.; Rohrlich, D. Action and passion at a distance. In Potentiality, Entanglement and Passion-at-a-Distance: Quantum Mechanical Studies for Abner Shimony, Volume Two (Boston Studies in the Philosophy of Science); Cohen, R.S., Horne, M., Stachel, J., Eds.; Springer: Dordrecht, The Netherlands, 1997; pp. 197-206. [CrossRef]

114. Krenn, G.; Svozil, K. Stronger-than-quantum correlations. Found. Phys. 1998, 28, 971-984. [CrossRef]

115. Popescu, S. Nonlocality beyond quantum mechanics. Nat. Phys. 2014, 10, 264-270. [CrossRef]

116. Herbert, N. FLASH-A superluminal communicator based upon a new kind of quantum measurement. Found. Phys. 1982, 12, 1171-1179. [CrossRef]

117. Svozil, K. What is wrong with SLASH? arXiv 2001, arXiv:0103166.

118. Swinburne, R. The Concept of Miracle; New Studies in the Philosophy of Religion; Palgrave Macmillan: London, UK, 1970. [CrossRef]

119. Frank, P. Das Kausalgesetz und seine Grenzen; Springer: Vienna, Austria, 1932.

120. Frank, P.; Cohen, R.S. (Eds.) The Law of Causality and its Limits (Vienna Circle Collection); Springer: Vienna, Austria, 1997. [CrossRef]

121. Melamed, Y.Y.; Lin, M. Principle of Sufficient Reason. In The Stanford Encyclopedia of Philosophy; Zalta, E.N., Ed.; Metaphysics Research Lab, Stanford University: Stanford, CA, USA, 2020.

122. Wigner, E.P. The unreasonable effectiveness of mathematics in the natural sciences. Richard Courant Lecture delivered at New York University, May 11, 1959. Commun. Pure Appl. Math. 1960, 13, 1-14. [CrossRef]

123. Berkeley, G. A Treatise Concerning the Principles of Human Knowledge; Skinner-Row: Dublin, Ireland, 1710.

124. Stace, W.T. The Refutation of Realism. Mind 1934, 43, 145-155. [CrossRef]

125. Stace, W.T. The Refutation of Realism. In Readings in Philosophical Analysis; Feigl, H., Sellars, W., Eds.; Appleton-Century-Crofts: New York, NY, USA, 1949; pp. 364-372. [CrossRef]

126. Goldschmidt, T.; Pearce, K.L. Idealism: New Essays in Metaphysics; Oxford University Press: Oxford, UK, 2017. [CrossRef]

127. Descartes, R. Meditations on First Philosophy; Translated by John Cottingham; Cambridge University Press: Cambridge, UK, 1996. 
128. Nietzsche, F. Ueber Wahrheit und Lüge im Außermoralischen Sinne; Digital Critical Edition of the Complete Works and Letters, Based on the Critical Text; Colli, G., Montinari, M., D'Iorio, P., Eds.; de Gruyter: Berlin, Germany, 2009.

129. Derrida, J. Et Cetera. In Deconstructions; Royle, N., Ed.; Palgrave Publishers Ltd. (Formerly Macmillan Press Ltd.): New York, NY, USA, 2000; Chapter 15. [CrossRef]

130. Artaud, A. Le Théâtre et Son Double; Gallimard: Paris, France, 1938.

131. Artaud, A. The Theatre and Its Double; Translated by Victor Corti; Alma Classics Limited: Richmond Surrey, UK, 2010.

132. Hertz, H. Prinzipien der Mechanik; Johann Ambrosius Barth (Arthur Meiner): Leipzig, Germany, 1894.

133. Hertz, H. The Principles of Mechanics Presented in a New Form; MacMillan and Co., Ltd.: New York, NY, USA, 1899.

134. Plato. The Republic; Translated by Tom Griffith; Ferrari, G.R.F., Ed.; Cambridge Texts in the History of Political Thought; Cambridge University Press: Cambridge, UK, 2000.

135. Feyerabend, P.K. Explanation, reduction, and empiricism. In Scientific Explanation, Space, and Time; Minnesota Studies in the Philosophy of Science; University of Minnesota Press: Minneapolis, MA, USA, 1962; Volume III, pp. $28-97$.

136. Feyerabend, P.K. Realism, Rationalism and Scientific Method; Philosophical Papers; Cambridge University Press: Cambridge, UK, 1981; Volume 1.

137. Kuhn, T.S. The Structure of Scientific Revolutions, 4th ed.; University of Chicago Press: Chicago, IL, USA, 2012.

138. Oberheim, E. On the historical origins of the contemporary notion of incommensurability: Paul Feyerabend's assault on conceptual conservativism. Stud. Hist. Philos. Sci. Part A 2005, 36, 363-390. [CrossRef]

139. Oberheim, E.; Hoyningen-Huene, P. The Incommensurability of Scientific Theories. In The Stanford Encyclopedia of Philosophy; Zalta, E.N., Ed.; Metaphysics Research Lab, Stanford University: Stanford, CA, USA, 2018.

140. Pigliucci, M. Nonsense on Stilts, 2nd ed.; University of Chicago Press: Chicago, IL, USA; London, UK, 2018,

141. Lakatos, I. The Methodology of Scientific Research Programmes; Philosophical Papers; Worrall, J., Currie, G., Eds.; Cambridge University Press: Cambridge, UK, 2012; Volume 1. [CrossRef]

142. Lakatos, I. Falsification and the methodology of scientific research programmes. In The Methodology of Scientific Research Programmes; Philosophical Papers; Cambridge University Press: Cambridge, UK, 2012; Volume 1. [CrossRef]

143. Schopenhauer, A. Die Welt als Wille und Vorstellung. Erster Band, 3rd ed.; Georg Müller: München, Germany, 1912.

144. Nietzsche, F. Also Sprach Zarathustra. Ein Buch für Alle und Keinen; Digital Critical Edition of the Complete Works and Letters, Based on the Critical Text; Colli, G., Montinari, M., D'Iorio, P., Eds.; de Gruyter: Berlin, Germany, 2009.

145. Nietzsche, F. Ecce Homo. Wie Man Wird, Was Man Ist; Digital Critical Edition of the Complete Works and Letters, Based on the Critical Text; Colli, G., Montinari, M., D’Iorio, P., Eds.; de Gruyter: Berlin, Germany, 2009.

146. Camus, A. Le Mythe de Sisyphe (English Translation: The Myth of Sisyphus); Gallimard: Paris, France, 1942.

147. Popper, K.R. Logik der Forschung; Springer: Vienna, Austria, 1934. [CrossRef]

148. Popper, K.R. The Logic of Scientific Discovery, 2nd ed.; Hutchinson \& Co and Routledge: New York, NY, USA, 2002. [CrossRef]

149. Klein, J.; Giglioni, G. Francis Bacon. In The Stanford Encyclopedia of Philosophy; Zalta, E.N., Ed.; Metaphysics Research Lab, Stanford University: Stanford, CA, USA, 2020.

150. Bridgman, P.W. The Logic of Modern Physics; Macmillan: New York, NY, USA, 1927.

151. Bridgman, P.W. A Physicist's Second Reaction to Mengenlehre. Scr. Math. 1934, 2, 101-117. $224-234$.

152. Bridgman, P.W. The Nature of Physical Theory; Dover Publications: New York, NY, USA, 1936.

153. Bridgman, P.W. Reflections of a Physicist; Philosophical Library: New York, NY, USA, 1950.

154. Bridgman, P.W. The Nature of Some of Our Physical Concepts; Philosophical Library: New York, NY, USA, 1952.

155. Hume, D. A Treatise of Human Nature: Texts; The Clarendon Edition of the Works of David Hume; Norton, D.F., Norton, M.J., Eds.; Oxford University Press: Oxford, UK, 2007; Volume 1, pp. 1739-1740. [CrossRef]

156. Hume, D. An Enquiry Concerning Human Understanding; Oxford World's Classics; Millican, P., Ed.; Oxford University Press: Oxford, UK, 2007.

157. Svozil, K. What Is so Special about Quantum Clicks? Entropy 2020, 22, 602. [CrossRef]

158. Aspect, A.; Grangier, P.; Roger, G. Experimental Tests of Realistic Local Theories via Bell's Theorem. Phys. Rev. Lett. 1981, 47, 460-463. [CrossRef]

159. Aspect, A.; Dalibard, J.; Roger, G. Experimental Test of Bell's Inequalities Using Time-Varying Analyzers. Phys. Rev. Lett. 1982, 49, 1804-1807. [CrossRef]

160. Zeilinger, A. Testing Bell's Inequalities with Periodic Switching. Phys. Lett. A 1986, 118, 1-2. [CrossRef]

161. Braunstein, S.L.; Kimble, H.J. A posteriori teleportation. Nature 1998, 394, 840-841. [CrossRef]

162. Bouwmeester, D.; Pan, J.W.; Daniell, M.; Weinfurter, H.; Zukowski, M.; Zeilinger, A. Reply: A posteriori teleportation. Nature 1998, 394, 841. [CrossRef]

163. Bouwmeester, D.; Pan, J.W.; Mattle, K.; Eibl, M.; Weinfurter, H.; Zeilinger, A. Experimental quantum teleportation. Nature 1997, 390, 575-579. [CrossRef]

164. Bennett, C.H.; Brassard, G.; Crépeau, C.; Jozsa, R.; Peres, A.; Wootters, W.K. Teleporting an unknown quantum state via dual classical and Einstein-Podolsky-Rosen channels. Phys. Rev. Lett. 1993, 70, 1895-1899. [CrossRef]

165. Svozil, K. Extensions of Hardy-type true-implies-false gadgets to classically obtain indistinguishability. Phys. Rev. A 2021, 103, 022204. [CrossRef]

166. Gold, M.E. Language identification in the limit. Inf. Control. 1967, 10, 447-474. [CrossRef] 
167. Blum, L.; Blum, M. Toward a mathematical theory of inductive inference. Inf. Control. 1975, 28, 125-155. [CrossRef]

168. Angluin, D.; Smith, C.H. Inductive Inference: Theory and Methods. ACM Comput. Surv. 1983, 15, 237-269. [CrossRef]

169. Adleman, L.M.; Blum, M. Inductive Inference and Unsolvability. J. Symb. Log. 1991, 56, 891-900. [CrossRef]

170. Li, M.; Vitányi, P.M.B. Inductive reasoning and Kolmogorov complexity. J. Comput. Syst. Sci. 1992, 44, 343-384. [CrossRef]

171. Gandy, R.O. Limitations to Mathematical Knowledge. In Logic Colloquium '80, Proceedings of the European Summer Meeting of the Association for Symbolic Logic, Prague, Czech Republic, 24-30 August 1980; van Dalen, D., Lascar, D., Smiley, J., Eds.; North Holland: Amsterdam, The Netherlands, 1982; pp. 129-146.

172. Svozil, K. Randomness \& Undecidability in Physics; World Scientific: Singapore, 1993. [CrossRef]

173. Svozil, K. Undecidability everywhere? In Boundaries and Barriers. On the Limits to Scientific Knowledge; Casti, J.L., Karlquist, A., Eds.; Addison-Wesley: Reading, MA, USA, 1996; pp. 215-237.

174. Svozil, K. Physical Unknowables. In Kurt Gödel and the Foundations of Mathematics; Baaz, M., Papadimitriou, C.H., Putnam, H.W., Scott, D.S., Harper, C.L., Jr., Eds.; Cambridge University Press: Cambridge, UK, 2011; pp. 213-251. [CrossRef]

175. Norton, J.D. Causation as Folk Science. Philos. Impr. 2003, 3, 1-22.

176. Sloane, N.J.A. A033307 Decimal Expansion of Champernowne Constant (or Mahler's Number), Formed by Concatenating the Positive Integers. 2019. Available online: https:/ / oeis.org/ A033307 (accessed on 8 September 2019).

177. Dow, S. Aristotle, the Kleroteria, and the Courts. Harv. Stud. Class. Philol. 1939, 50, 1-34. [CrossRef]

178. Toffoli, T. The Role of the Observer in Uniform Systems. In Applied General Systems Research: Recent Developments and Trends; Klir, G.J., Ed.; Springer US: New York, NY, USA, 1978; pp. 395-400. [CrossRef]

179. Fredkin, E. Digital mechanics. An informational process based on reversible universal cellular automata. Physica 1990, D45, 254-270. [CrossRef]

180. Svozil, K. A constructivist manifesto for the physical sciences-Constructive re-interpretation of physical undecidability. In The Foundational Debate: Complexity and Constructivity in Mathematics and Physics. Vienna Circle Institute Yearbook; Schimanovich, W.D., Köhler, E., Stadler, F., Eds.; Springer: Berlin/Heidelberg, Germany, 1995; pp. 65-88. [CrossRef]

181. Bostrom, N. Are We Living in a Computer Simulation? Philos. Q. 2003, 53, 243-255. [CrossRef]

182. Maxwell, J.C. Does the progress of Physical Science tend to give any advantage to the opinion of Necessity (or Determinism) over that of the Contingency of Events and the Freedom of the Will? In The life of James Clerk Maxwell. With a Selection from Their Correspondence and Occasional Writings and a Sketch of Their Contributions to Science, 2nd ed.; Campbell, L., Garnett, W., Eds.; MacMillan: London, UK, 1999.

183. Norton, J.D. The Dome: An Unexpectedly Simple Failure of Determinism. Philos. Sci. 2008, 75, 786-798. [CrossRef]

184. van Strien, M. The Norton Dome and the Nineteenth Century Foundations of Determinism. J. Gen. Philos. Sci. 2014, 45, 167-185. [CrossRef]

185. Smoluchowski, M. Experimentell nachweisbare, der üblichen Thermodynamik widersprechende Molekularphänomene. Phys. Z. 1912, 13, 1069-1080.

186. Uffink, J. Subjective Probability and Statistical Physics. In Probabilities in Physics; Beisbart, C., Hartmann, S., Eds.; Oxford University Press: Oxford, UK, 2011; pp. 25-49. [CrossRef]

187. Hamilton, W.D. The Evolution of Altruistic Behavior. Am. Nat. 1963, 97, 354-356. [CrossRef]

188. Watzlawick, P.; Beavin, J.H.; Jackson, D.D. Pragmatics of Human Communication: A Study of Interactional Patterns, Pathologies, and Paradoxes; W. W. Norton \& Company: New York, NY, USA, 1967.

189. Born, M. Zur Quantenmechanik der Stoßvorgänge. Z. Für Phys. 1926, 37, 863-867. [CrossRef]

190. Hiebert, E.N. Common Frontiers of the Exact Sciences and the Humanities. Phys. Perspect. 2000, 2, 6-29. [CrossRef]

191. Stöltzner, M. Vienna Indeterminism: Mach, Boltzmann, Exner. Synthese 1999, 119, 85-111. [CrossRef]

192. Schweidler, E.V. Über Schwankungen der radioaktiven Umwandlung. In Premier Congres International Pour L'etude de la Radiologie et de I'ionisation tenu a Liege du 12 au 14 Septembre 1905; H. Dunod \& E. Pinat: Paris, France, 1906; pp. 1-3.

193. Exner, F.S. Über Gesetze in Naturwissenschaft und Humanistik: Inaugurationsrede gehalten am 15. Oktober 1908; Hölder, Ebooks on Demand Universitätsbibliothek Wien: Vienna, Austria, 2016. Available online: https://hdl.handle.net/11353/10.451413 (accessed on 22 April 2021).

194. Armstrong, D.M. What Is a Law of Nature?; Cambridge Studies in Philosophy, Cambridge University Press: Cambridge, UK, 1983. [CrossRef]

195. van Fraassen, B.C. Laws and Symmetry; Oxford University Press: Oxford, UK, 2003. [CrossRef]

196. Calude, C.; Meyerstein, F.W. Is the universe lawful? Chaos Solitons Fractals 1999, 10, 1075-1084. [CrossRef]

197. Rosen, J. Lawless Universe: Science and the Hunt for Reality; The John Hopkins University Press: Balrtimreo, MD, USA, 2010.

198. Calude, C.S.; Meyerstein, W.F.; Salomaa, A. The Universe is Lawless or "Panton chrematon metron anthropon einai". In Computable Universe: Understanding and Exploring Nature as Computation; Zenil, H., Ed.; World Scientific: Singapore, 2013; pp. 525-537. [CrossRef]

199. Yanofsky, N. Chaos makes the multiverse unnecessary. Nautilus 2017, 66, 1-16.

200. Mueller, M.P. Could the physical world be emergent instead of fundamental, and why should we ask? arXiv 2017, arXiv:1712.01816.

201. Cabello, A. Physical origin of quantum nonlocality and contextuality. arXiv 2019, arXiv:1801.06347.

202. Calude, C.S.; Svozil, K. Spurious, Emergent Laws in Number Worlds. Philosophies 2019, 4, 17. [CrossRef] 
203. Clark, K.J. Is God a Bowler or a Curler? In Proceedings of the Randomness and Providence Workshop, Providence, RI, USA, 9-12 May 2017.

204. Voltaire, F. A Philosophical Dictionary; Derived from The Works of Voltaire, A Contemporary Version; E.R. DuMont: New York, NY, USA, 1764.

205. Galouye, D.F. Simulacron 3; Bantam Books: New York, NY, USA, 1964.

206. Egan, G. Permutation City; Hachette: Paris, France, 1994.

207. Svozil, K. Extrinsic-intrinsic concept and complementarity. In Inside Versus Outside; Springer Series in Synergetics; Atmanspacher, H., Dalenoort, G.J., Eds.; Springer: Berlin/Heidelberg, Germany, 1994; Volume 63, pp. 273-288. [CrossRef]

208. Eccles, J.C. The Mind-Brain Problem Revisited: The Microsite Hypothesis. In The Principles of Design and Operation of the Brain; Eccles, J.C., Creutzfeldt, O., Eds.; Springer: Berlin/Heidelberg, Germany, 1990; pp. 549-572. [CrossRef]

209. Kochen, S.; Specker, E.P. The Problem of Hidden Variables in Quantum Mechanics. J. Math. Mech. 1967, 17, 59-87. [CrossRef]

210. Everett, H., III. In The Everett Interpretation of Quantum Mechanics: Collected Works 1955-1980 with Commentary; Barrett, J.A., Byrne, P., Eds.; Princeton University Press: Princeton, NJ, USA, 2012.

211. Jaynes, E.T. Probability Theory as Logic. In Maximum Entropy and Bayesian Methods; Fougère, P.F., Ed.; Springer: Dordrecht, The Netherlands, 1990; pp. 1-16. [CrossRef]

212. Freud, S. Ratschläge für den Arzt bei der psychoanalytischen Behandlung. In Gesammelte Werke. Chronologisch Geordnet. Achter Band. Werke aus den Jahren 1909-1913; Freud, A., Bibring, E., Hoffer, W., Kris, E., Isakower, O., Eds.; Fischer: Frankfurt am Main, Germany, 1999; pp. 376-387.

213. Freud, S. Recommendations to Physicians Practising Psycho-Analysis. In The Standard Edition of the Complete Psychological Works of Sigmund Freud, Volume XII (1911-1913): The Case of Schreber, Papers on Technique and Other Works; Freud, A.F.A., Strachey, A., Tyson, A., Eds.; The Hogarth Press and the Institute of Psycho-Analysis: London, UK, 1958; pp. 109-120.

214. Hahn, H. Die Bedeutung der wissenschaftlichen Weltauffassung, insbesondere für Mathematik und Physik. Erkenntnis 1930, 1, 96-105. [CrossRef]

215. Carnap, R. Überwindung der Metaphysik durch logische Analyse der Sprache. Erkenntnis 1931, 2, 219-241. [CrossRef]

216. Carnap, R. The Elimination of Metaphysics Through Logical Analysis of Language. In Logical Positivism; Translated by Arp, A.; Ayer, A.J., Ed.; Free Press: New York, NY, USA, 1959; pp. 60-81.

217. Gödel, K. Über formal unentscheidbare Sätze der Principia Mathematica und verwandter Systeme. Monatshefte für Mathematik und Physik 1931, 38, 173-198. [CrossRef]

218. Turing, A.M. On computable numbers, with an application to the Entscheidungsproblem. Proc. Lond. Math. Soc. Ser. 2 1937, 42, 230-265. [CrossRef]

219. Turing, A.M. On computable numbers, with an application to the Entscheidungsproblem. Proc. Lond. Math. Soc. Ser. 2 1938, 43 544-546. [CrossRef]

220. Smullyan, R.M. Gödel's Incompleteness Theorems; Oxford Logic Guides 19; Oxford University Press: Oxford, UK, 2020. [CrossRef]

221. Smullyan, R.M. Recursion Theory for Metamathematics; Oxford Logic Guides 22; Oxford University Press: Oxford, UK, 2020. [CrossRef]

222. Smullyan, R.M. Diagonalization and Self-Reference; Oxford Logic Guides; Clarendon Press: Oxford, UK, 1994 ; Volume 27.

223. Chaitin, G.J. Algorithmic Information Theory; Cambridge Tracts in Theoretical Computer Science; Cambridge University Press: Cambridge, UK, 2003; Volume 1. [CrossRef]

224. Augustine of Hippo. Confessions; Translated by Thomas Williams; Hackett Publishing Company, Inc.: Indianapolis, IN, USA, 2019. 